\title{
Arbuscular Mycorrhizal Colonisation Modifies the Water Relations of Young Transplanted Grapevines (Vitis)
}

M. van Rooyen ${ }^{1}$, A. Valentine ${ }^{2 *}$ and E. Archer ${ }^{3 * *}$

(1) Department of Botany, Stellenbosch University, Private Bag X1, 7602 Matieland (Stellenbosch), South Africa

(2) Department of Environmental Sciences, Faculty of Applied Sciences, Cape Peninsula University of Technology, PO Box 652, 8000 Cape Town, South Africa

(3) Department of Viticulture \& Oenology, Stellenbosch University, Private Bag X1, 7602 Matieland (Stellenbosch), South Africa

Submitted for publication: June 2002

Accepted for publication: August 2004

Key words: Water relations, photosynthesis, mycorrhizas, transplantation

The effect of arbuscular mycorrhizal (AM) colonisation on the alleviation of transplantation shock in young grapevines was investigated. One-year-old grapevines (Sauvignon blanc on Richter 99), colonised with Glomus etunicatum (Becker and Gerdemann), were cultivated in an atmosphere-controlled tunnel. Water relations, leaf photosynthetic parameters and growth characters were evaluated. AM colonisation enhanced the photosynthetic performance of host plants, but had no influence on biomass and mineral nutrition of the transplanted hosts. The increased photosynthetic rates of the AM plants were related to improved water relations. Stomatal conductance, transpiration rate and midday xylem water potential were higher in the AM hosts during the transplanted period. These results indicate that $\mathrm{AM}$ inoculation can influence the water relations of transplanted grapevine rootstocks, thereby improving photosynthetic performance and potential survival during the initial growth stages of the host plants.

The role of arbuscular mycorrhiza (AM) in enhancing plant growth and yield of crops has been previously reported (Bolan, 1991). In this regard one of the greatest potential benefits of AM fungi for host plants is the increase in biomass and growth of the host plants. This increase in growth and biomass may be caused by the host plant's increased ability to acquire essential nutrients and water (Ruiz-Lozano \& Azcon, 1995). The beneficial effect of mycorrhizae is of special importance to plants such as grapevines that have a coarse and poorly branched root system. Grapevines appear to be reliant on AM fungal colonisation for normal growth and development (Menge et al., 1983; Karagiannidis et al., 1995; Biricolti et al., 1997; Linderman \& Davis, 2001). Furthermore, it was found that coarse-rooted species, such as vines (Motosugi et al., 2002) are more reliant on AM colonisation than fine-rooted species (Bolan, 1991; Eissenstat, 1992).

The fungal species and the rootstock cultivar will determine many of the benefits attributed to the symbiosis (Menge et al.,1983; Schubert et al.,1988; Karagiannidis et al., 1997). Schubert et al. (1988) inoculated different rootstock cultivars with different AM fungi and found that certain fungal species combined with specific rootstocks increased plant growth to a greater extent than other combinations did. The percentage colonisation, degree of growth response and nutritional benefits of AM colonisation of vine roots will vary according to the AM fungal species and the rootstock cultivar involved (Linderman \& Davis, 2001; Schreiner, 2003).
Vineyards infected with soil pathogens such as phylloxera often require fumigation treatments. However, the fumigant clears the soil of both desired and undesired soil microbes, including AM fungi (Menge et al., 1983; Linderman \& Davis, 2001). Therefore the inoculation of vines before planting in fumigated soils is needed to ensure AM fungal colonisation of the vine roots. Menge et al. (1983) reported that non-AM vines planted in fumigated soils had stunted growth compared to the inoculated vines. This transplantation shock of the vines may be related to root-system damage (Waschkies et al., 1993), which may impair water and nutrient uptake. The phenomenon of transplantation shock has been found to be reduced by inoculating the vines with AM fungi (Linderman \& Davis, 2001). It is currently not known how AM colonisation could mediate an alleviation of the transplantation shock in young grapevines, but the evidence of root-system damage (Waschkies et al., 1993) suggests that AM fungi may improve water relations and nutrient access of host plants. The objective of this study was therefore to assess the contribution of a single-strain AM inoculum on the host-water relations and the consequent impact of this on mineral nutrition, photosynthesis and growth of transplanted grapevine rootstocks. The rootstocks were inoculated during transplantation and the host performance was assessed after 90 days of growth.

\section{MATERIALS AND METHODS}

\section{Growth conditions}

One-year-old grafted grapevine cuttings (Vitis vinifera L. cv. Sauvignon blanc, grafted onto Richter 99 rootstocks) were plant- 
ed in 20-litre pots, containing irradiated ( $20 \mathrm{kGy})$ filter sand with a grain size of $0.51 \mathrm{~mm}$ and $\mathrm{pH}$ of 7 . Registered, commercial Vitis vinifera L. cv. Sauvignon blanc grafted onto Richter 99 rootstocks were selected to have similar shoot thickness and root development. The plants were grown for 90 days in a north-facing tunnel at the University of Stellenbosch, Western Cape, South Africa. The maximum daily photosynthetically active irradiance was between 700 and $800 \mu \mathrm{mol} \mathrm{m} \mathrm{m}^{-2} \mathrm{~s}^{-1}$ and the average day/night temperatures were $23 / 19^{\circ} \mathrm{C}$. The transplanted grapevines were watered with a standard Long-Ashton nutrient solution modified to contain $\mathrm{NO}_{3}{ }^{-} / \mathrm{NH}_{4}{ }^{+}$as $\mathrm{N}$ source and $100 \mu \mathrm{M}$ P. The solution was added every seven days at field capacity (21) of the sand.

\section{Inoculation}

The inoculum consisted of a single-strain pure culture (spores and fragments of roots and hyphae in an inert carrier, collected from pot culture) of an AM species, Glomus etunicatum (supplied by Dr C. Straker from University of the Witwatersrand). The spore density of the inoculum was 12 spores/g. The AM grapevines were inoculated and the control plants received a filtered inoculum solution, which was prepared by filtering the inoculum through a $37 \mu \mathrm{m}$ mesh to remove the mycorrhizal fungal material. Inoculation was conducted by spreading the inoculum around the roots in the planting hole. The pot was then filled up with the sand covering the roots and the inoculum. This ensured that the propagated roots were immediately in contact with the AM fungal propagules.

\section{Plant harvest}

At 90 days of pot culture the physiological measurements were taken and the plants were harvested. The leaf areas of the plants were measured with a leaf area meter (Licor, model LI-3000, Lambda Instruments Corporation, USA) and the water potential was determined with a pressure chamber (PNS intruments Co. Oregon USA). The roots were carefully blotted dry, root pieces of the root were randomly cut off, weighed and stored in a vial with $50 \%$ ethanol $(\mathrm{v} / \mathrm{v})$ solution for estimation of mycorrhizal colonisation. The components were dried at $80^{\circ} \mathrm{C}$ for more than $72 \mathrm{~h}$ and weighed to determine the dry weight.

The biomass parameters were calculated as follows. Leaf-area ratio is the ratio of total leaf area relative to total plant mass. Specific leaf mass describes the density of leaves, expressed as leaf mass per leaf area $\left(\mathrm{kg} / \mathrm{m}^{2}\right)$. Relative growth rate is the specific growth $(\mathrm{mg})$ for an existing plant mass (g) over time (mg/g/day). Growth rate is the average growth for a given period (g/day). The biomass $\mathrm{N}$ and $\mathrm{P}$ use efficiencies express the ratio of total plant dry matter accumulated per amount of total plant $\mathrm{N}$ or $\mathrm{P}(\mathrm{g} \mathrm{dw} / \mathrm{mmol} \mathrm{N}$ or $\mathrm{P})$.

\section{Mycorrhizal colonisation}

During plant harvest, the thin lateral roots were removed and stored in 50\% ethanol. Root segments were cleared in $2.5 \% \mathrm{KOH}$ in an Autoclave for 6 minutes (hot clearing). Afterwards, the $\mathrm{KOH}$ was rinsed from the segments and acidified with $1 \% \mathrm{HCL}$ for 24 $\mathrm{h}$ at room temperature. The roots were stained with $0.05 \%$ Analine blue in $70 \%$ acidified glycerol for $48 \mathrm{~h}$ at room temperature. Roots were cut into $1 \mathrm{~cm}$ pieces and randomly selected to be packed on slides. They were subsequently examined at x 400 magnification under a light microscope. Infection was determined according to the methods described by Brundrett et al. (1994).

\section{Photosynthesis}

The youngest fully expanded leaf for each plant was used for the photosynthetic determinations. The photosynthetic rate $(\mathrm{Pn})$, stomatal conductance (Gs) and transpiration rate (E) were determined at midday, using a portable infrared gas analyser (LiCor). Photosynthetic nitrogen-use efficiency (PNUE) and photosynthetic phosphorus-use efficiency (PPUE) were obtained by dividing $\mathrm{Pn}$ by either the leaf $\mathrm{N}$ or $\mathrm{P}$ concentration, respectively. Photosynthetic water-use efficiency (PWUE) was calculated from measurements of $\mathrm{Pn}$ and transpiration rate. Intercellular $\mathrm{CO}_{2}$ response curves were determined using the facility on the infrared gas analyser, by manually adjusting the $\mathrm{CO}_{2}$ concentration in the leaf chamber. The $\mathrm{CO}_{2}$ response curves were used to calculate electron transport capacity and RUBISCO activity, using the equations of Watanabe et al. (1994).

\section{Chemical analyses}

Chlorophyll analyses were performed on leaf discs taken from the same leaves which were used for the gas exchange measurements. Chlorophyll was extracted at $4{ }^{\circ} \mathrm{C}$ in acetone. The resulting extract was centrifuged at $3000 \mathrm{~g}$ for 3 minutes, and the chlorophyll concentration was determined according to the method of Arnon (1949) by measuring the absorbance at 646, 663 and 710 $\mathrm{nm}$ in a spectrophotometer. The oven-dried $\left(72 \mathrm{~h}, 80^{\circ} \mathrm{C}\right)$ plant material of each treatment was milled in a Wiley mill (A.H. Thomas, Philadelphia, Pa, USA) using a 60 mesh screen, for leaf, stem and root material. The plant material was analysed by BEMLABS (Somerset West, RSA) for N and P.

\section{Xylem water potential}

Xylem water potentials (XWP) were taken at midday, using a pressure chamber (PNS Instruments Co. Oregon, USA). A terminal branch bearing the first fully expanded leaf was placed in the pressure bomb, with the leaf inside the chamber and cut surface of the stem protruding from the chamber. The pressure was gradually increased, until the xylem sap evenly covered the cut surface. At this point the pressure was turned off and recorded as the water potential.

\section{Statistical analyses}

Plants were spaced in a random block design. The percentage data were arcsine transformed (Zar, 1984). The influence of the factor, mycorrhizal inoculation, was tested with a one-way analysis of variance (1-way ANOVA) and the differences between treatments were separated using a post hoc Student Newman Kuels (SNK), multiple comparison test (SuperANOVA version. 6.11 for Macintosh). Different letters indicate significant differences between treatments $(\mathrm{P} \leq 0.05), \mathrm{n}=5$.

\section{RESULTS}

Roots inoculated with live AM had $61 \%$ colonisation, whilst the control plants remained non-mycorrhizal for the duration of the trial (Table 1). The presence of AM colonisation did not influence the biomass of the host plants and there were no differences in growth parameters between AM and non-AM plants (Table 1). $\mathrm{N}$ and $\mathrm{P}$ nutrition of the host plants also remained unaffected by AM colonisation (Table 2).

In spite of the absence of differences between AM and non-AM biomass and nutrition, the net photosynthetic ( $\mathrm{Pn}$ ) gas exchange and leaf water relations were significantly influenced by AM 


\section{TABLE 1}

Biomass-parameters of 90-day-old +AM and -AM grapevines, grown in pots containing sterilised filter sand. The +AM inoculum was live Glomus etunicatum, whilst the -AM inoculum was an irradiated Glomus etunicatum sample, containing a filtrate of the non-mycorrhizal microbes present in the live inoculum. The plants received a standard Long-Ashton nutrient solution in which the $\mathrm{N}$ concentration was modified to $2 \mathrm{mM} \mathrm{NO}_{3} / \mathrm{NH}_{4}$ and $100 \mu \mathrm{M}$ P. The values represent averages with a standard error $( \pm)$. The different letters indicate significant differences between $+\mathrm{AM}$ and -AM treatments in each row $(\mathrm{P} \leq 0.05)$.

\begin{tabular}{lrrrr}
\hline Parameters & \multicolumn{2}{c}{-AM } & \multicolumn{1}{c}{ +AM } \\
\hline Leaf data & \multicolumn{5}{c}{} \\
\hline leaf dry mass (g) & 1.33 & $\pm 0.12 \mathrm{a}$ & 1.62 & $\pm 0.13 \mathrm{a}$ \\
leaf fresh mass $(\mathrm{g})$ & 4.54 & $\pm 0.44 \mathrm{a}$ & 5.87 & $\pm 0.62 \mathrm{a}$ \\
leaf area $\left(\mathrm{m}^{2}\right)$ & 291.73 & $\pm 30.53 \mathrm{a}$ & 378.20 & $\pm 31.84 \mathrm{a}$ \\
leaf number & 24.33 & $\pm 1.67 \mathrm{a}$ & 25.67 & $\pm 2.91 \mathrm{a}$ \\
leaf area ratio & 0.15 & $\pm 0.01 \mathrm{a}$ & 0.13 & $\pm 0.01 \mathrm{a}$ \\
specific leaf mass $\left(\mathrm{kg} / \mathrm{m}^{2}\right)$ & 4.58 & $\pm 0.14 \mathrm{a}$ & 4.29 & $\pm 0.03 \mathrm{a}$ \\
Biomass & & & & \\
\hline root dry mass (g) & 18.07 & $\pm 2.75 \mathrm{a}$ & 20.80 & $\pm 1.93 \mathrm{a}$ \\
shoot dry mass (g) & 23.44 & $\pm 3.12 \mathrm{a}$ & 24.31 & $\pm 4.61 \mathrm{a}$ \\
total plant dry mass $(\mathrm{g})$ & 44.72 & $\pm 6.12 \mathrm{a}$ & 49.35 & $\pm 6.84 \mathrm{a}$ \\
root:shoot & 0.77 & $\pm 0.04 \mathrm{a}$ & 0.90 & $\pm 0.13 \mathrm{a}$ \\
plant relative growth rate & & & & \\
(mg/g/day) & 0.981 & $\pm 1.129 \mathrm{a}$ & 0.844 & $\pm 3.391 \mathrm{a}$ \\
plant growth rate (g/day) & 0.497 & $\pm 0.068 \mathrm{a}$ & 0.548 & $\pm 0.076 \mathrm{a}$
\end{tabular}

Arbuscular mycorrhizal

colonisation

\begin{tabular}{lllll}
\hline root colonisation with $\mathrm{AM}(\%)$ & 0 & $\pm 0.0 \mathrm{a}$ & 61.10 & $\pm 7.72 \mathrm{~b}$
\end{tabular}

\section{TABLE 2}

$\mathrm{N}$ and $\mathrm{P}$ concentrations of 90-day-old +AM and -AM grapevines, grown in pots containing sterilised filter sand. The +AM inoculum was live Glomus etunicatum, whilst the -AM inoculum was an irradiated Glomus etunicatum sample, containing a filtrate of the non-mycorrhizal microbes present in the live inoculum. The plants received a standard Long-Ashton nutrient solution in which the $\mathrm{N}$ concentration was modified to $2 \mathrm{mM} \mathrm{NO}_{3} / \mathrm{NH}_{4}$ and $100 \mu \mathrm{M}$ P. The values represent averages with a standard error $( \pm)$. The different letters indicate significant differences between $+\mathrm{AM}$ and $-\mathrm{AM}$ treatments in each row $(\mathrm{P} \leq 0.05)$.

\begin{tabular}{lrrrr}
\hline Parameters & \multicolumn{1}{c}{-AM } & \multicolumn{1}{c}{ +AM } \\
\hline $\begin{array}{l}\mathrm{N} \text { concentration } \\
\text { (mmol N/g dw) }\end{array}$ & & & & \\
\hline root N & 9.28 & $\pm 1.37 \mathrm{a}$ & 1.62 & $\pm 0.13 \mathrm{a}$ \\
stem N & 5.90 & $\pm 0.90 \mathrm{a}$ & 5.87 & $\pm 0.62 \mathrm{a}$ \\
leaf N & 20.06 & $\pm 1.14 \mathrm{a}$ & 22.09 & $\pm 0.51 \mathrm{a}$ \\
biomass N-use efficiency & & & & \\
(g dw/ mmol N) & 0.08 & $\pm 0.01 \mathrm{a}$ & 0.06 & $\pm 0.005 \mathrm{a}$ \\
P concentration & & & & \\
(mmol P/g dw) & & & & \\
\hline root P & 1.58 & $\pm 0.24 \mathrm{a}$ & 1.87 & $\pm 0.43 \mathrm{a}$ \\
stem P & 1.05 & $\pm 0.16 \mathrm{a}$ & 1.18 & $\pm 0.04 \mathrm{a}$ \\
leaf P & 3.26 & $\pm 0.33 \mathrm{a}$ & 3.23 & $\pm 0.27 \mathrm{a}$ \\
biomass P-use efficiency & & & & \\
(g dw/mmol P) & 0.47 & $\pm 0.08 \mathrm{a}$ & 0.38 & $\pm 0.04 \mathrm{a}$ \\
\hline
\end{tabular}

\section{TABLE 3}

Phototsynthetic parameters of 90-day-old +AM and -AM grapevines, grown in pots containing sterilised filter sand. The +AM inoculum was live Glomus etunicatum, whilst the -AM inoculum was an irradiated Glomus etunicatum sample, containing a filtrate of the non-mycorrhizal microbes present in the live inoculum. The plants received a standard Long-Ashton nutrient solution in which the $\mathrm{N}$ concentration was modified to $2 \mathrm{mM}$ $\mathrm{NO}_{3} / \mathrm{NH}_{4}$ and $100 \mu \mathrm{M}$ P. The values represent averages with a standard error $( \pm)$. The different letters indicate significant differences between $+\mathrm{AM}$ and $-\mathrm{AM}$ treatments in each row $(\mathrm{P} \leq 0.05)$.

\begin{tabular}{|c|c|c|c|c|}
\hline \multirow{2}{*}{$\frac{\text { Parameters }}{\text { Photon yield }}$} & \multicolumn{2}{|c|}{$-\mathbf{A M}$} & \multicolumn{2}{|c|}{$+\mathrm{AM}$} \\
\hline & 0.231 & $\pm 0.050 \mathrm{a}$ & 0.206 & $\pm 0.019 \mathrm{a}$ \\
\hline $\begin{array}{l}\text { Rubisco activity } \\
\left(\mu \mathrm{mol} \mathrm{CO}_{2} \mathrm{~m}^{-2} \cdot \mathrm{s}^{-1}\right)\end{array}$ & 29.885 & $\pm 0.749 \mathrm{a}$ & 34.486 & $\pm 3.825 \mathrm{a}$ \\
\hline $\begin{array}{l}\text { Electron transport activity } \\
\left(\mu \mathrm{mol} \mathrm{CO} 2 \mathrm{~m}^{-2} \cdot \mathrm{s}^{-1}\right)\end{array}$ & 124.607 & $\pm 2.665 \mathrm{a}$ & 131.155 & $\pm 15.519 \mathrm{a}$ \\
\hline $\begin{array}{l}\text { Chlorophyll a } \\
\left(\mu \mathrm{mol} . \mathrm{m}^{-2}\right)\end{array}$ & 393.938 & $\pm 52.841 \mathrm{a}$ & 397.483 & $\pm 19.378 \mathrm{a}$ \\
\hline $\begin{array}{l}\text { Chlorophyll b } \\
\left(\mu \mathrm{mol} \cdot \mathrm{m}^{-2}\right)\end{array}$ & 130.658 & $\pm 20.391 \mathrm{a}$ & 166.839 & $\pm 28.851 \mathrm{a}$ \\
\hline Chlorophyll a:b & 3.056 & $\pm 0.200 \mathrm{a}$ & 2.492 & $\pm 0.321 \mathrm{a}$ \\
\hline $\begin{array}{l}\text { Total Chlorophyll } \\
\left(\mu \mathrm{mol} \cdot \mathrm{m}^{-2}\right)\end{array}$ & 524.596 & $\pm 72.215 \mathrm{a}$ & 564.322 & $\pm 48.218 \mathrm{a}$ \\
\hline $\begin{array}{l}\text { Photosynthetic } \\
\text { N-use effciency }\end{array}$ & & & & \\
\hline$\left(\mu \mathrm{mol} \mathrm{CO} 2 \mathrm{mmol}^{-1} \mathrm{~N} \mathrm{~m}^{-2} \cdot \mathrm{s}^{-1}\right)$ & 0.018 & $\pm 0.003 \mathrm{a}$ & 0.012 & $\pm 0.001 \mathrm{a}$ \\
\hline $\begin{array}{l}\text { Photosynthetic P-use effciency } \\
\left(\mu \mathrm{mol} \mathrm{CO} 2 \mathrm{mmol}^{-1} \mathrm{P} \mathrm{m}^{-2} \cdot \mathrm{s}^{-1}\right)\end{array}$ & 0.003 & $\pm 0.001 \mathrm{a}$ & 0.002 & $\pm 0.000 \mathrm{a}$ \\
\hline
\end{tabular}

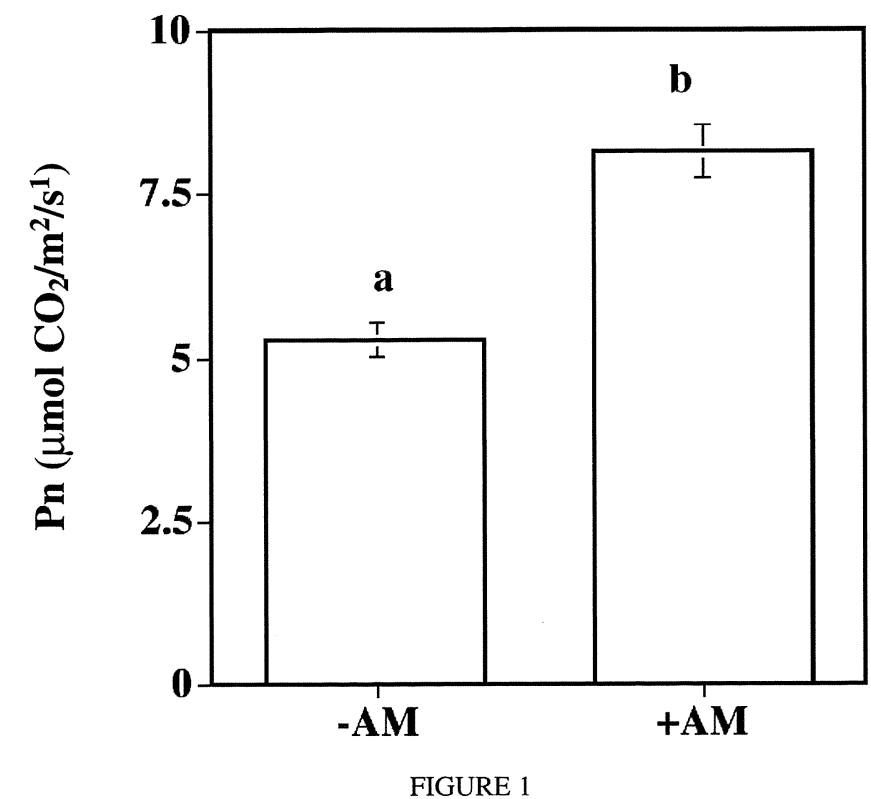

Photosynthetic rates $(\mathrm{Pn})$ of 90-day-old +AM and -AM grapevines, grown in pots containing sterilised filter sand. The +AM inoculum was live Glomus etunicatum, whilst the -AM inoculum was an irradiated Glomus etunicatum sample, containing a filtrate of the non-mycorrhizal microbes present in the live inoculum. The plants received a standard Long-Ashton nutrient solution in which the $\mathrm{N}$ concentration was modified to $2 \mu \mathrm{M} \mathrm{NO}_{3} / \mathrm{NH}_{4}$ and $100 \mu \mathrm{M}$ P. The values represent averages with a standard error $( \pm)$. The different letters indicate significant differences between the two treatments $(\mathrm{P} \leq 0.05)$. 


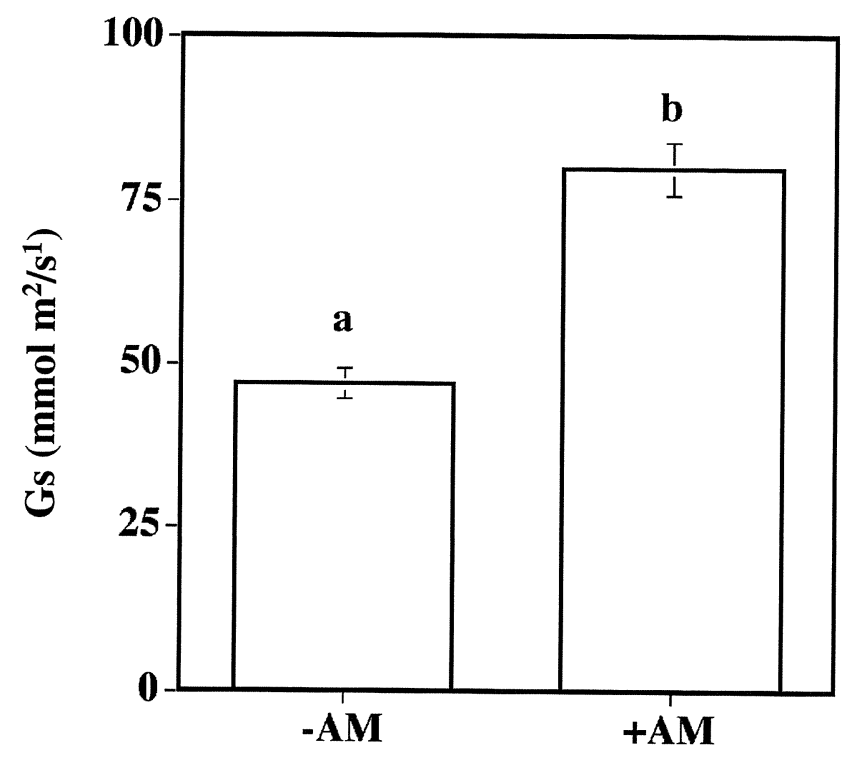

FIGURE 2

Stomatal conductance (GS) of 90-day-old +AM and -AM grapevines, grown in pots containing sterilised filter sand. The +AM inoculum was live Glomus etunicatum, whilst the -AM inoculum was an irradiated Glomus etunicatum sample, containing a filtrate of the non-mycorrhizal microbes present in the live inoculum. The plants received a standard Long-Ashton nutrient solution in which the $\mathrm{N}$ concentration was modified to $2 \mathrm{mM} \mathrm{NO} / \mathrm{NH}_{4}$ and $100 \mu \mathrm{M}$ P. The values represent averages with a standard error $( \pm)$. The different letters indicate significant differences between the two treatments $(P \leq 0.05)$.

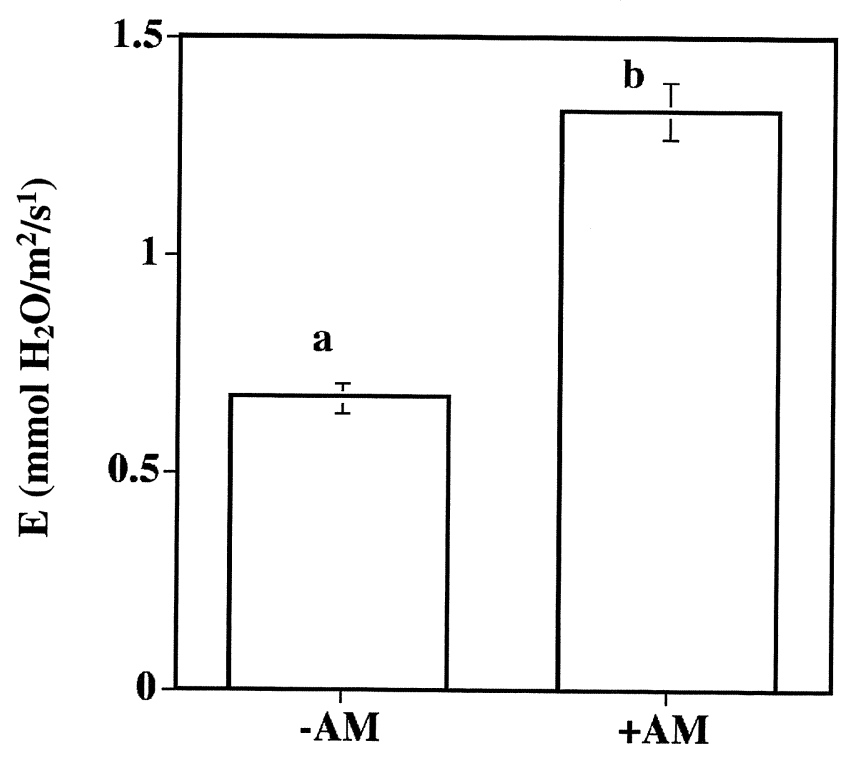

FIGURE 4

Transpiration rate (E) of 90-day-old $+\mathrm{AM}$ and $-\mathrm{AM}$ grapevines, grown in pots containing sterilised filter sand. The +AM inoculum was live Glomus etunicatum, whilst the -AM inoculum was an irradiated Glomus etunicatum sample, containing a filtrate of the non-mycorrhizal microbes present in the live inoculum. The plants received a standard Long-Ashton nutrient solution in which the $\mathrm{N}$ concentration was modified to $2 \mathrm{mM} \mathrm{NO} \mathrm{N}_{3} / \mathrm{NH}_{4}$ and $100 \mu \mathrm{M}$ P. The values represent averages with a standard error ( \pm ). The different letters indicate significant differences between the two treatments $(\mathrm{P} \leq 0.05)$.

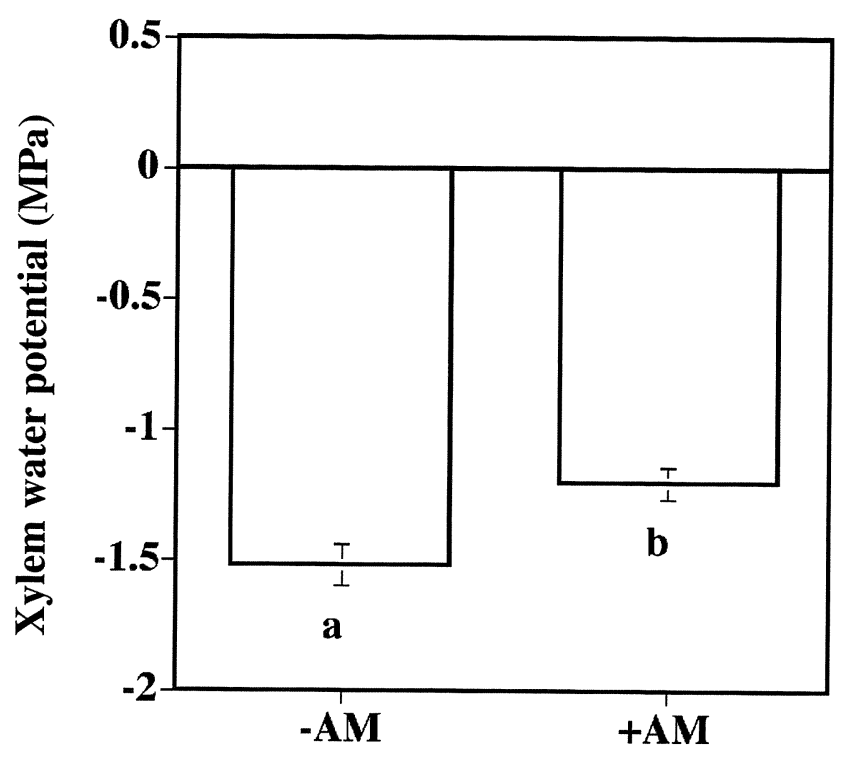

FIGURE 3

Xylem sap pressure potential (XWP) of 90-day-old +AM and -AM grapevines, grown in pots containing sterilised filter sand. The +AM inoculum was live Glomus etunicatum, whilst the -AM inoculum was an irradiated Glomus etunicatum sample, containing a filtrate of the non-mycorrhizal microbes present in the live inoculum. The plants received a standard Long-Ashton nutrient solution in which the $\mathrm{N}$ concentration was modified to $2 \mathrm{mM} \mathrm{NO}_{3} / \mathrm{NH}_{4}$ and $100 \mu \mathrm{M}$ P. The values represent averages with a standard error $( \pm)$. The different letters indicate significant differences between the two treatments $(P \leq 0.05)$.

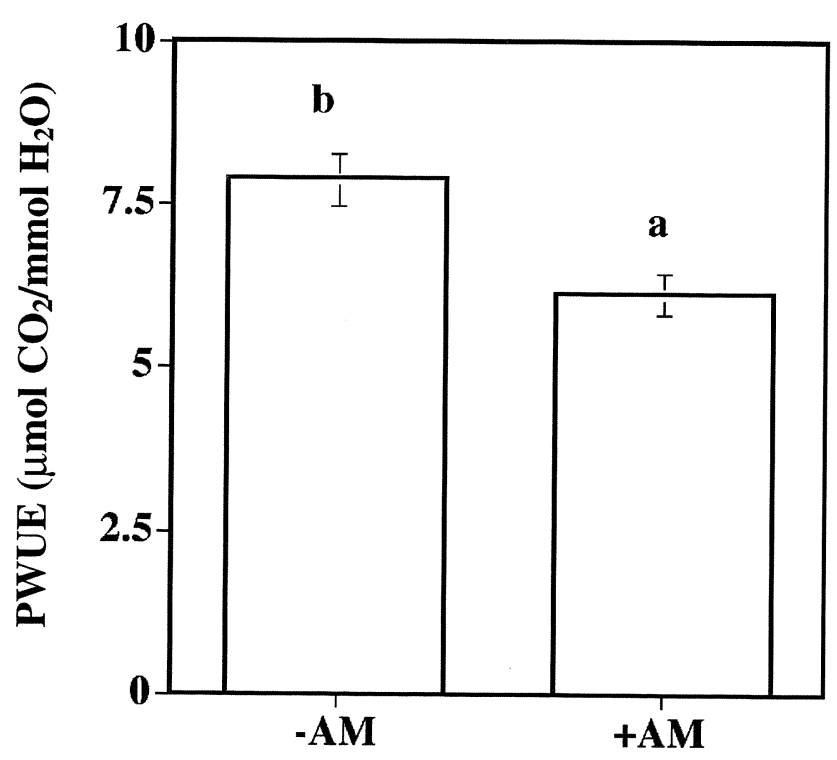

FIGURE 5

Photosynthetic water use efficiency (PWUE) of 90-day-old +AM and -AM grapevines, grown in pots containing sterilised filter sand. The +AM inoculum was live Glomus etunicatum, whilst the -AM inoculum was an irradiated Glomus etunicatum sample, containing a filtrate of the non-mycorrhizal microbes present in the live inoculum. The plants received a standard Long-Ashton nutrient solution in which the $\mathrm{N}$ concentration was modified to $2 \mathrm{mM} \mathrm{NO} 3 / \mathrm{NH}_{4}$ and $100 \mu \mathrm{M}$ P. The values represent averages with a standard error $( \pm)$. The different letters indicate significant differences between the two treatments $(P \leq 0.05)$. 
colonisation. The Pn rate was higher in the AM leaves compared to the non-AM leaves (Fig. 1), but this was not related to other leaf photosynthetic parameters (Table 3 ). In this regard, RUBISCO activity, electron transport capacity, chlorophyll levels, photosynthetic nutrient-use efficiencies and photon yield were unaffected by AM colonisation (Table 3). Instead, the increased Pn corresponded with enhanced stomatal conductance (Gs) (Fig. 2) and transpiration rates (E) (Fig. 4) in the AM leaves. Midday xylem water potentials (XWP) were lower (less negative) in the AM plants, implying less water stress than in the non-AM controls (Fig. 3). However, the higher photosynthetic water-use efficiency (PWUE) of the AM plants indicates that AM host plants lost more water than non-AM plants during photosynthetic $\mathrm{CO}_{2}$ fixation (Fig. 5).

\section{DISCUSSION}

The absence of increases in biomass and mineral nutrition of AM colonised grapevines contradicts earlier findings of mycorrhizal benefits to host grapevines (Possingham \& Obbink, 1971; Menge et al., 1983). However, the improved rate of photosynthesis (Pn) in AM plants is congruent with other studies of herbaceous hosts (Allen et al., 1981; Levy \& Kirkun, 1980; Valentine et al., 2001; 2002), as well as grapevine hosts (Nikolaou et al., 2003b). In particular the present study concurs with Nikolaou et al., (2003b), who also demonstrated that AM-colonised vines had higher $\mathrm{CO}_{2}$ assimilation rates than uncolonised vines, but with no increase in the biomass of the host plants. Since the increase of Pn in the AM plants occurred in the absence of improved nutrient status or the derived photosynthetic parameters, it is therefore proposed to be related to an AM sink effect or an AM-induced change in water relations.

The association of the increase in Pn and the percentage of AM colonisation suggests a relationship between AM colonisation and carbohydrate availability, as proposed by Valentine et al. (2001; 2002). It is well known that the demand for photo-assimilates can stimulate the rate of Pn (Neales \& Incoll, 1968; Herold, 1980; Foyer, 1987) and since a large proportion of photosynthetic product is allocated to the root of AM plants (Marschner, 1995; Jacobsen \& Rosendahl, 1990), this is one potential mechanism for the observed increases in Pn of AM plants.

The improved water relations, as another potential mechanism of the AM stimulation of host Pn, have been causally related to Pn via increases in the stomatal conductance (Gs) of the AM plants (Allen et al., 1981; Brown \& Bethelenfalvay, 1987; Fitter, 1988; Valentine et al., 2001; 2002). In the present study the improved Gs, transpiration rate and xylem water potential in AM grapevines, provide sufficient evidence that the water status was increased by AM colonisation. Previous studies (Giovanetti \& Mosse, 1980; Graham \& Syverston, 1984) found that the altered water status of the AM plants was closely associated with an improved host nutrition, particularly $\mathrm{P}$. These findings do not concur with the current study, where host nutrition was not affected by AM status. However, the present work does concur with other findings (Read, 1992; Sylvia \& Williams, 1992; Koide, 1993) where it was proposed that mycorrhizal infection can facilitate a significant increase of water flux independent of changes in the nutrient status of the host. Water uptake by root tissue may therefore be a result of the presence of AM fungi on these roots, as was found by Ruiz-Lozano \& Azcon (1995). Motosugi et al. (2002) also reported that AM-colonised roots were more efficient in the uptake of water compared to uncolonised roots. Nikolaou et al. (2003a) determined that AM vines have an improved water status and drought-sensitive rootstocks showed greater growth when colonised by an AM fungus under non-irrigated conditions. AM fungi can therefore aid in the uptake of water and contribute to an improved water status in vines, enabling the vines to grow under low irrigation or survive water-stressed conditions. Interestingly, the improved water status by the AM fungi may also have caused the AM plants to allow greater water loss during photosynthetic $\mathrm{CO}_{2}$ assimilation. This less efficient PWUE suggests that the host plants are able to spend more water under conditions of sufficient water supply by AM fungal symbionts.

\section{CONCLUSIONS}

It is concluded that inoculation of transplanted grapevines with AM fungi may improve the plant water status and thereby increase the potential alleviation of transplantation shock. The AM mechanism of action on water relations appears to be independent from an improved nutrient status. Although AM may contribute to a healthier plant in pot culture, further studies are required to assess whether the same benefits are possible under field conditions. The potential of such future work is supported by the suggestion of Allen \& Allen (1986) that AM fungi are important in sustainable agriculture because they improve plantwater relations and drought resistance of host plants.

\section{LITERATURE CITED}

Allen, E.B. \& Allen, M.F., 1986. Water relations of xeric grasses in the field: interactions of mycorrhizas and competition. New Phytologist 104, 559-571.

Arnon, D.I., 1949. Copper enzymes in isolated chloroplast: polyphenoloxidases in Beta vulgaris. Plant Physiol. 24, 1-15.

Allen, M.F., Smith, W.K., Moore, T.S. \& Christensen, M., 1981. Comparative water relations and photosynthesis of mycorrhizal and non-mycorrhizal Bouteloua gracilis. New Phytologist 88, 683-693.

Biricolti, S., Ferrini, F., Rinaldelli, E., Tamantini, I. \& Vignozzi, N., 1997. AM fungi and soil lime content influence rootstock growth and nutrient content. Am. J. Enol. Vitic. 48, 93-99.

Bolan, N.S., 1991. A critical review on the role of mycorrhizal fungi in the uptake of phosphorous by plants. Plant Soil 134, 189-207.

Bolan, N.S., Robson, A.D. \& Barrow, N.J., 1987. Effects of vesicular-arbuscular mycorrhiza on the availability of iron phosphates to plants. Plant Soil 99, 401-410.

Brown, M.S. \& Bethlenfalvay, G.J., 1987. Glycine-Glomus-Rhizobium symbiosis. VI. Photosynthesis in nodulated, mycorrhizal, or N- and P-fertilized soybean plants. Plant Physiol. 85, 120-123.

Brundrett, M., Melville, L. \& Peterson, L., 1994. Practical Methods in Mycorrhiza Research. Micologue Publications.

Eissenstat, D.M., 1992. Cost and benefits of constructing roots of small diameter J.Plant Nut. 15, 763-782.

Fitter, A.H., 1988. Water relations of red clover Trifolium pratense L. as affected by VA mycorrhizal infection and phosphorus supply before and during drought. J. Exp. Bot. 39, 595-603.

Foyer, C.H., 1987. The basis for source-sink interaction in leaves. Plant Physiol. \& Bioch. 25, 649-657.

Giovantti, M. \& Mosse, B., 1980. An evaluation of techniques for measuring vesicular-arbuscular infection in roots. New Phytologist 84, 489-500.

Graham, J.H. \& Syverston, J.P., 1984. Influence of vesucular-arbuscular mycorrhiza on the hydraulic conductivity of roots of two citrus root stocks. New Phytologist 97, 277-284.

Herold, A., 1980. Regulation of photosynthesis by sink activity - the missing link New Phytologist 86, 131-144. 
Jacob, J. \& Lawlor, D.W., 1991. Stomatal and mesophyll limitations of photosynthesis in phosphate deficient sunflower, maize and wheat plants. J. Exp. Bot. 42 1003-1011.

Jakobsen, I. \& Rosendahl, L., 1990. Carbon flow into soil and external hyphae from roots of mycorrhizal cucumber plants. New Phytologist 115, 77-83.

Karagiannidis, K., Nikolaou, N. \& Mattheou, A., 1995. Influence of three VAmycorrhiza species on the growth and nutrient uptake of three grapevine rootstocks and one table grape cultivar. Vitis $34,85-89$.

Karagiannidis, K., Velemis, D. \& Stavropoulos, N., 1997. Root colonisation and spore population by VA-mycorrhizal fungi in four grapevine rootstocks. Vitis 36 , 57-60.

Koide, R.T., 1993. Physiology of the mycorrhizal plant. In: Tommerup, I.C. (ed.) Advances in Plant Pathology, Vol. 9, Mycorrhiza synthesis. New York Academic Press. pp. 33-54.

Levy, Y. \& Krikun, J., 1980. Effects of vesicular-arbuscular mycorrhiza on Citrus jambhiri water relations. New Phytologist 85, 25-31.

Linderman, R.G. \& Davis, E.A., 2001. Comparative response of selected grapevine rootstocks and cultivars to inoculation with different mycorrhizal fungi. Am. J. Enol. Vitic. 52, 8-11.

Marschner, H., 1995. Mineral Nutrition of Higher Plants. London Academic Press, p. 570.

Menge, J.A., Raski, D.J., Lider, L.A., Johnson, E.L.V., Jojes, N.O., Kissler, J.J. \& Hemstreet, C.L., 1983. Interactions between mycorrhizal fungi, soil fumigation and growth of grapes in California. Am. J. Enol. Vitic. 34, 117-121.

Motosugi, H., Yamamoto, Y., Naruo, T., Kitabyashi, H. \& Ishi, T., 2002. Comparison of the growth and leaf mineral concentrations between three grapevine rootstocks and their corresponding tetraploids inoculated with an arbuscular mycorrhizal fungus Gigaspora margarita. Vitis 41, 21-25.

Neales, T.F. \& Incoll, L.D., 1968. The control of leaf photosynthesis by the leve of assimilate concentration in the leaf. Areview of the hypothesis. Botanical Review 34, 107-125.

Nikolaou, N., Angelopoulos, K.\& Karagiannidis, N., 2003a. Effects of drough stress on mycorrhizal and non-mycorrhizal Cabernet Sauvignon grapevine, grafted onto various rootstocks. Experimental Agriculture 39, 241-252.

Nikolaou, N.A., Koukourikou, M., Angelopoulos, K. \& Karagiannidis, N., 2003b Cytokinin content and water relations of Cabernet Sauvignon grapevine exposed to water stress. J. Hort. Sci. \& Biotech. 78, 113-118.
Nikolaou, N., Karagiannidis, N., Koundouras, S. \& Fysarakis, I., 2002. Effects of different $\mathrm{P}$ sources in soil on increasing growth and mineral uptake of mycorrhiza Vitis vinifera L. (cv Victoria) vines. Journal international des sciences de la vigne et du vin 36, 195-204.

Possingham, J.V. \& Obbink, J.G., 1971. Endotrophic mycorrhiza and the nutrition of grape vines. Vitis 10, 120-130.

Read, D.J., 1992. The mycorrhizal mycelium. In: Allen, M.F. (ed.). Mycorrhizal Functioning. An Integrative Plant-Fungal Process. New York. Chapman and Hall. pp. 102-133.

Ruiz-Lozano, J.M. \& Azcon, R., 1995. Hyphal contribution to water uptake in mycorrhizal plants as affected by the fungal species and water status. Physiologia Plantarum 95, 472-478.

Schubert, A., Cammarata, S. \& Eynard, I., 1988. Growth and root colonization of grape vines inoculated with different mycorrhizal endophytes. Hort. Sci. 23, 302 303 .

Schubert, A. \& Cravero, M.C., 1985. Occurrence and infectivity of vesiculararbuscular mycorrhizal fungi in north-western Italy vineyards. Vitis 24, 129-138.

Schreiner, R.P., 2003. Mycorrhizal colonisation of grapevine rootstocks under field conditions. Am. J. Enol. Vitic. 54, 143-149.

Sylvia, D.M. \& Williams, S.E., 1992. Vesicular-arbuscular mycorrhizae and enviromental stresses. In: Bethelenfalvay, G.J. \& Linderman, R.G. (eds). Mycorrhizae in Sustainable Agriculture. ASA Special Publication No. 54. Madison. pp. 101124.

Valentine, A.J., Osborne, B.A. \& Mitchell, D.T., 2001. Interactions between phosphorus supply and total nutrient availability on mycorrhizal colonization, growth and photosynthesis of cucumber. Scientia Horticulturae 88, 177-189.

Valentine, A.J., Osborne, B.A. \& Mitchell, D.T., 2002. Form of inorganic nitrogen influences mycorrhizal colonsation and photosynthesis of cucumber. Scientia Horticulturae 92, 229-239.

Waschkies, C., Schropp, A. and Marschner, H., 1993. Relations between replant disease, growth parameters and mineral nutrition status of grapevines (Vitis sp.) Vitis $32,69-76$

Watanabe, N., Evans, J.R. \& Chow, S., 1994. Changes in the photosynthetic properties of Australian wheat cultivars over the last century. Aust. J. Plant Physiol. 21, 169-183.

Zar, J.H., 1984. Biostatistical Analysis- Second edition. Englewood Cliffs. N.J. Prentice-Hall, Inc. pp. 239-241. 